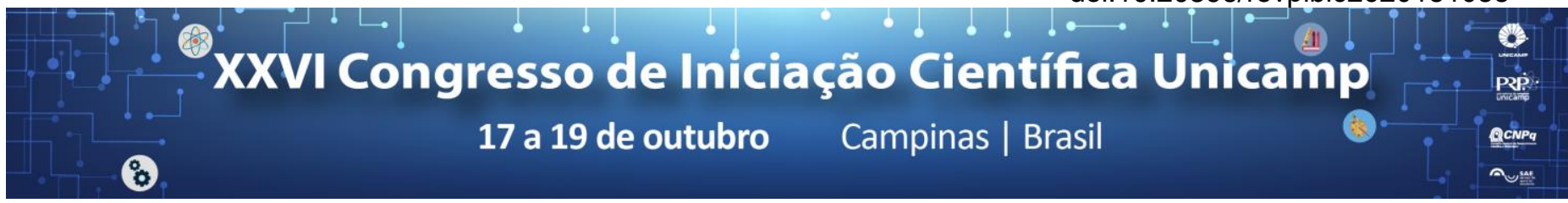

\title{
Clinical and Molecular Analysis of Children with Wiskott-Aldrich Syndrome to indicate Bone Marrow Transplantation
}

\section{Nathalie Cardim, Maria Marluce dos Santos Vilela.}

\begin{abstract}
Resumo
Wiskott-Aldrich Syndrome (WAS) is a genetic disease linked to the $\mathrm{X}$ chromosome, characterized by recurrent infections, autoimmunity, malignancy, eczema and hemorrhage. Mutations in the WAS gene alter the coding of the WASp protein, expressed mainly in the cytoplasm of hematopoietic cells, with functions of actin polymerization, signaling events and cytoskeletal rearrangement. According to severity, there are four phenotypes described: classical form (WAS), X-linked thrombocytopenia (XLT), X-linked intermittent thrombocytopenia (IXLT) and X-linked neutropenia $(\mathrm{XLN})$. Only the mutation analysis was shown to be of limited value in predicting the clinical phenotype. However, the analysis of protein expression in lymphocytes has been very successful in predicting this phenotype. On the other hand, it is not yet known which patients with XLT phenotype may progress to the classical form and for this reason there are controversies about the indication of bone marrow transplantation in these patients. This study aims to perform a clinical, laboratory and molecular analysis of pediatric patients diagnosed with WAS under our clinical follow-up at Hospital das Clínicas of UNICAMP and follow-up patients at other Brazilian Reference Centers of Primary Immunodeficiency.
\end{abstract}

\section{Palavras-chave:}

Wiskott-Aldrich Syndrome, phenotype, bone marrow transplant.

\section{Introdução}

A Síndrome de Wiskott-Aldrich (WAS) é uma doença genética caracterizada por infecções recorrentes, autoimunidade, malignidade, eczema e hemorragia. De acordo com a gravidade, há quatro fenótipos ${ }^{1}$ : a forma clássica (WAS), trombocitopenia ligada ao $X(X L T)$, trombocitopenia intermitente ligada ao $X$ (IXLT) e neutropenia ligada ao $X(X L N)$. Trata-se de uma doença rara, mas de morbidade importante, que necessita de estudos a fim de esclarecer quanto ao diagnóstico e ao manejo, visando tratamento efetivo.

Foram coletados dados por meio da revisão de prontuários dos pacientes em seguimento no HC-UNICAMP; a partir desses resultados e da leitura de artigos, construímos um questionário clínico laboratorial online para ser aplicado em nível nacional, sendo que até o momento 5 Centros de Referência em Imunodeficiência Primária aceitaram participar.

O objetivo deste estudo é realizar uma análise clínica dos pacientes pediátricos e tentar associá-la ao estudo genético molecular, para indicação ou não do transplante de medula óssea (TMO).

\section{Resultados e Discussão}

Até o momento foram analisados 7 prontuários no HCUNICAMP, sendo $100 \%$ pacientes do sexo masculino. A análise estatística indicou um padrão de achados clínicos (Figura 1), sendo mais frequentes petéquias $(71,4 \%)$, dermatite atópica (81\%) e hematoquesia $(57,1 \%)$. Em relação aos antecedentes patológicos, constatou-se uma prevalência alta de otite $(71,4 \%)$ e pneumonia $(57,1 \%)$. Ainda, a análise dos hemogramas demonstrou plaquetopenia grave (<20 mil plaquetas $\left./ \mathrm{mm}^{3}\right)$ em $100 \%$ dos pacientes analisados. Em relação ao $\mathrm{TMO}, 33,3 \%$ dos pacientes foram submetidos à terapia, mostrando evolução favorável, principalmente com o aumento no número das plaquetas, em estudo longitudinal. Estamos aguardando a resposta dos demais Centros, para que tenhamos uma amostra maior e melhor acurácia dos resultados obtidos.

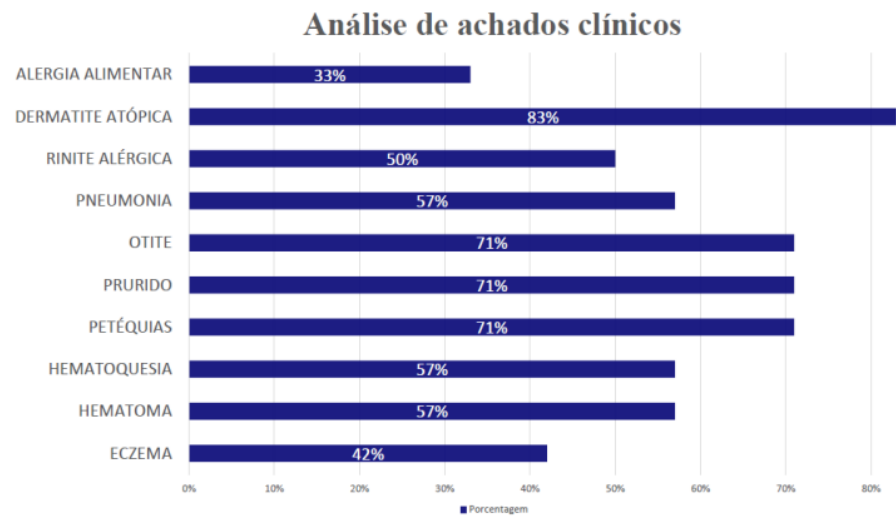

Figura 1. Análise de alguns dados clínicos obtidos de prontuários de pacientes em seguimento no $\mathrm{HC}$ UNICAMP.

\section{Conclusões}

A análise dos dados obtidos indica um padrão de sinais e sintomas, bem como a análise laboratorial, com padrão de plaquetopenia grave. Em relação ao TMO, a evolução se mostra favorável com diminuição no número de infecções graves e processos hemorrágicos. A etapa final deste projeto compilará os dados deste Centro (HCUNICAMP) com outros Centros Nacionais de Referência em Imunodeficiência Primária, os quais estamos aguardando a resposta do formulário eletrônico.

\section{Agradecimentos}

Agradecemos ao apoio financeiro do CNPq.

${ }^{1}$ Ochs, HD, Filipovich, AH et al. Wiskott-Aldrich Syndrome: diagnosis, clinical and laboratory manifestations, and treatment. 